\title{
An Interdisciplinary, Multi-Institutional Design Experience for Freshman En- gineering and Art Students
}

\section{Prof. Steven P. Marra, Johns Hopkins University}

Steven P. Marra received his B.S. degree from the University of Pittsburgh in 1993, and his M.S. and Ph.D. degrees from The Johns Hopkins University, Baltimore, MD, in 1998 and 2001, respectively, all in mechanical engineering. He is currently an Associate Teaching Professor in Mechanical Engineering at The Johns Hopkins University. His research interests include soft and hard tissue biomechanics, nonlinear mechanics of solids, mechanics of tissue damage, and undergraduate engineering education.

\section{Prof. Jenna Adele Frye, Maryland Institute College of Art}

Jenna is a self-described maker, teacher, and joker living and working in Baltimore, Maryland. Her creative work and ideas about educating artists have been showcased nationally and at several annual conferences including the National Association of Schools of Art and Design, The Association of Independent Colleges of Art and Design and The College Art Association. Frye is Assistant Department Chair of First Year Experience at the Maryland Institute College of Art where she also founded the college's first student-run maker space: The Make Cool Stuff Lab. You're likely to find her designing nerdy toys and games for her students to learn with, fiddling with the latest techno-crafts or maybe just playing with blocks. Jenna holds a Bachelor of Science in Psychology as well as an MA in Digital Art and an MFA in Sculpture.

\section{Prof. Edon Muhaxheri, Maryland Institute College of Art}

Edon is a multidisciplinary artist with a particular interest in digital arts and moving sculptures. His teaching portfolio includes digital fabrication prototyping, and courses on the design and making of mechanical sculptures. For 19 years, he has contributed in the visual and conceptual identity of private businesses, public enterprises, non-governmental organizations, and public figures.

\section{Ms. Laure Drogoul, Maryland Institute College of Art}

Laure Drogoul is an interdisciplinary artist, educator, and cobbler of situations who lives in Baltimore, Maryland. Laure works with a wide range of media including projects in which she creates sculpture, performance, and theatrical events that invite the viewer to be an active participant. She has exhibited widely, including The International House of Japan in Tokyo, Corcoran Gallery of Art, Washington Project for the Arts, The Walters Museum, Baltimore Museum of Art, and The Center for Architecture in New York as well as many street corners, alleys, and underutilized urban spaces.She has received Maryland State Artist Awards and a Franklin Furnace Award for performance art and has been a recipient of a US/Japan Creative Artist Fellowship. Laure holds a BFA from Temple University and MFA in Sculpture from the Maryland Institute College of Art. In 2006 Ms.Drogoul was honored with The Janet and Walter Sondheim Prize. 


\title{
An Interdisciplinary, Multi-Institutional Design Experience for Freshman Engineering and Art Students
}

\begin{abstract}
In the spring of 2018, 44 first-year mechanical engineering students from the Johns Hopkins University Whiting School of Engineering and 34 first-year art students from the Maryland Institute College of Art joined together into 18 teams to complete a semester-long design project. The students were given an open-ended design problem, a relatively small set of design requirements and constraints, and a budget of $\$ 100$ per team. An exhibition was hosted at the end of the semester at which the students' projects were presented to the public. This work describes the logistical, pedagogical, and social challenges encountered by the instructors and facilitators in creating and implementing this interdisciplinary and multi-institutional design assignment.
\end{abstract}

Introduction

Successful engineers must be able to work effectively on interdisciplinary projects and as members of multidisciplinary teams [1]-[3]. This is also true for many creative arts professionals, especially those who work in fields driven by technological innovation [4]. Several collaborative projects involving both engineering and creative/fine arts students have been reported in recent years, including

- Design of automobile option packages at Howard University [5]

- Creation of "technology-mediated" sculptural works at the University of Waterloo [6]

- Design and construction of an interactive sculpture at Binghamton University [7]

- Various projects combining engineering with aerial photography, music, dance, theater, and drawing at Valparaiso University [8],[9]

The collaborative engineering-art project assignment described in this work differs from those listed above in several ways. The students involved in this work were all first-year students, whereas the above projects were all at the capstone/senior-level. This work involved collaborations between students from two completely independent institutions. This work also involved a greater number of distinct projects (18) than those listed above.

This paper also differs slightly from those listed above in that the focus is not on the student outcomes of the project assignment, but rather on the challenges encountered by the instructors and facilitators in producing and implementing this interdisciplinary and multi-institutional assignment, with the hope of enlightening others who may be attempting or considering such an endeavor in the future.

Background

First-year students from two separate and distinct institutions joined together in the spring of 2018 to create exhibits of engineering and art for a public viewing. Freshman mechanical engineering majors from the Johns Hopkins University Whiting School of Engineering and First Year Experience (FYE) students from the Maryland Institute College of Art were assigned a 
collaborative design project and worked together throughout the spring semester to design, build, and test their creative ideas.

Johns Hopkins University (JHU) is a research university located in Baltimore, Maryland. The design project assignment was part of a new (first time offered) 1-credit course MechE Freshman Lab II in which 34 male and 10 female freshman students were enrolled. Most of the JHU students had completed fall courses in which they learned about engineering graphics (hand sketching, drawing standards, basic CAD) and the engineering design process (problem definition, ideation, concept development, prototyping, testing, and evaluation). The students were also introduced to topics such as materials science, manufacturing, gears, and mechanisms. The fall MechE Freshman Lab I also included a purely mechanical (no motors or electronics) design project. Topics covered in the spring MechE Freshman Lab II course included microcontrollers (Arduinos), sensors, electric motors, and internal combustion engines. The MechE Freshman Lab II course was split into four 3-hour sections per week. Three of the sections met on Thursdays (9am-12pm, 12-3pm, 3-6pm) and one section met on Fridays (12$3 \mathrm{pm})$. The number of students per section were 10, 18, 10, and 6, respectively. The course had one instructor and each section had one teaching assistant. The design project assignment was worth $30 \%$ of the students' final course grade.

The Maryland Institute College of Art (MICA) is an art and design school, also located in Baltimore, Maryland. The design project assignment was part of two separate 3-credit FYE courses: Body/World/Machine, in which students ( 2 male, 14 female) explore the role of the body, social space, and the media through intensive studio production in a range of formats, and Prototype/Situate/Fabricate, in which students (6 male, 12 female) create, represent, respond, and reflect on form, function, and structures in space. Each course met on Thursdays from 9am$3 \mathrm{pm}$, and each had one instructor and one teaching assistant.

The buildings in which the JHU MechE Freshman Lab II course and the MICA FYE courses were taught are slightly less than two (2) miles apart.

\section{Project Planning}

We began planning the design project in December of 2016. Collaborations between JHU and MICA were not uncommon, and the two institutions continue to work together on various endeavors (e.g. the JHU-MICA Film Centre). However, this was the first time we, the faculty involved in the design project, worked together.

We had several reasons for wanting to orchestrate a collaborative design project for our students. The opportunity for our students to work with others from outside of their discipline and culture was a huge motivator, and we were confident the experience would improve their teamwork, communication, and social/empathic skills. Since we had never attempted this kind of collaboration before, we were intrigued by the challenge of doing it, and by the prospect of learning from the experience in hopes that similar JHU-MICA design collaborations could occur in the future. The idea of our students combining art and engineering was exciting to us. As educators we were interested in learning about each other's respective disciplines and 
institutions, and of gaining new pedagogical insights throughout the process. We also believed the project would bring positive publicity to our schools, our students, and ourselves.

We agreed that the spring 2018 semester would be the best time to assign the project. This gave us plenty of time to develop the actual project assignment and to plan out our various course curricula and syllabi accordingly. Waiting until the spring semester also allowed us to know further in advance the total number of students who would be participating in the project. This decision also gave the students at each school more time to get to know each other before introducing them to their cross-town teammates.

In developing the project assignment, and based on the number of students enrolled in our courses, we decided to combine the classes into 18 teams, with 2-3 JHU students and 2 MICA students in each. The students were assigned to their respective teams based on the courses (MICA) and sections (JHU) in which they were enrolled. We attempted to keep the teams gender-balanced.

We wanted to challenge the teams to create something to meet a very general objective, within a framework of specific requirements and constraints, including a budget. We also wanted the teams to show off their works to the public at the end of the semester.

\section{The Design Project Assignment}

The design project was assigned to the students on Thursday, February 8, 2018. MICA classes for the spring 2018 semester started one week ahead of JHU classes, and this day coincided with the second week of classes for the JHU students and the third week of classes for the MICA students.

The project objective assigned to each team was to design and fabricate something that will "make your world better." Note that the assignment was not to make the world better, but rather to improve their own personal lives in some way. Our expectation was for the students to talk with each other and discover things they had in common, and then create something to eliminate a nuisance they all have, or celebrate something they all enjoy, or make it easier for them to do a chore, for example. Inspiration for this assignment came from the "life hacks" movement, and so we named the project "Hack Your Life."

Whatever each team created had to meet the following list of requirements and constraints:

- It had to be interactive/participatory (i.e. it had to respond to specific actions of the user/spectator).

- It had to have articulated moving parts (i.e. it had to be kinetic).

- It could not require the user/spectator to "reset" it after each response.

- It had to include at least five (5) different physical materials, of which at least one material had to be "soft" (e.g. cloth, foam, liquid) and at least one had to be "hard" (e.g. metal, wood, stiff plastic).

- It had to be of reasonable size for the available exhibition space.

- It had to pass a safety inspection by all three instructors before it was installed in the exhibition space. 
Each team was allowed to request up to $\$ 50$ worth of parts/materials from us, and each team was allowed to spend up to $\$ 50$ of their own money on the project (per team).

Basic machine shop and prototyping equipment (e.g. drill presses, band saws, laser cutters, 3D printers, hand tools) were available for students to use at both schools.

The final project exhibition was scheduled for April 26 ${ }^{\text {th }}, 2018$. As luck would have it, the entire second floor of the building in which the MICA classes were taught was empty at the time and due for a complete renovation during the coming summer. We were delighted to be granted this space for the students' exhibition. It was close to the MICA classrooms, very spacious, free for us to use, and the students had free reign to paint the walls, hang things from the ceiling, and alter the structure in almost any way they desired.

The project grades for the JHU students were determined by the quality of their final work, a final design report from each team (JHU students only), and the quality of their individual design project notebooks. The project grades for the MICA students were determined by the quality of the final work, the quality of the students' individual preliminary sketches, and the quality of their individual documentation of the final project.

\section{Expected Obstacles}

We anticipated two major logistical challenges for the students: 1) lack of convenient transportation between JHU and MICA, and 2) scheduling conflicts with two of the JHU sections.

JHU and MICA each provide several free, local transportation services for their students. However, no free service was available to transport the students from one campus to the other. We scheduled several combined in-class work sessions for the students throughout the semester and arranged for special shuttle services to drive the students back and forth on these days. However, we also wanted the students to meet with their teammates regularly outside of class to work on their projects. Most of the students did not have access to an automobile and so if they wanted to visit another campus their options were to either pay for a taxi/Uber/Lyft ride or take a city bus to the closest stop and then walk for approximately 20 minutes. Since the students were still new to the city, and often had to transport parts and materials between the campuses, walking was not a preferred option.

The combined in-class work sessions could only take place on Thursdays from 9am to 3pm because this was the only time each week when the MICA students met for their FYE classes (see Figure 1). We arranged transportation for the JHU students in sections 1 and 2 to meet with their MICA teammates during these sessions, but assumed that most of the JHU students in sections 3 and 4 would be unable to join them due to conflicts with their other Thursday courses. This meant that several JHU students could not participate fully in the project. 


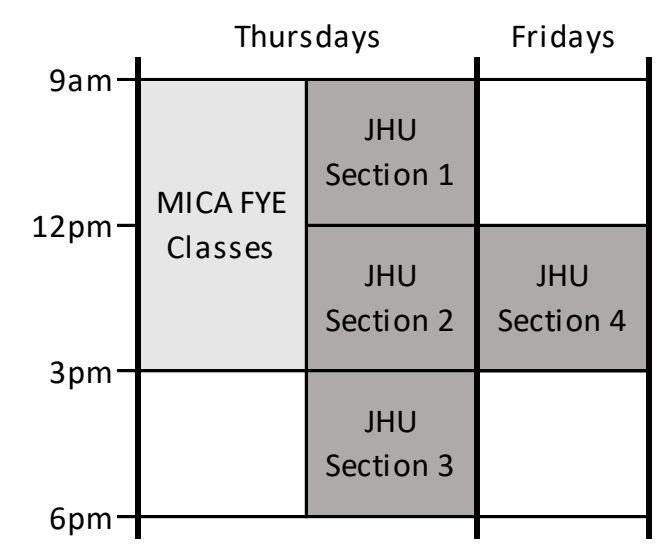

Figure 1-Weekly schedule of MICA and JHU classes

Other concerns we had about the project, in addition to the logistical obstacles, were:

- Would the students be able to communicate effectively with each other? For example, the words "material" and "installation" have different meanings in engineering and in art. The problem of miscommunication between engineering and art students due to their use of disciplinary-specific vocabulary has been noted previously by Wuerffel and Will [8].

- Would the students divide the work such that the JHU students were only doing the technical work while the MICA students were only doing the artistic work, instead of learning from each other? As Fleischmann and Hutchison note, the "silo" mentality of disciplines is a recurring obstacle to collaboration, even within a single university [4].

- Would the students' personalities, their various strengths and weaknesses, differing goals, and possible lack of self-awareness lead to personal conflicts among team members? As Fleischmann and Hutchison note, new participants in multidisciplinary teams are often unprepared for the challenges of managing interpersonal relationships with members from other disciplines [4]. Given the youthfulness of our students, we expected to encounter such issues.

- Would the students create anything controversial or objectionable? We did not want to stifle their creativity and free expression, but we also wanted the final exhibition to be fully inclusive.

\section{Administrative Support}

We created a website for the project assignment to provide the students with information, inspiration, and a means for submitting their purchase requests and project proposals (see below). The project brief was posted on the website and included information about the specifications, how to contact the various instructors and facilitators, and details about the various equipment available to the students. We also posted information on transportation options and links to several inspirational websites (e.g. life hacks, high tech art installations).

To help ease the inherent awkwardness and discomfort that often occurs when meeting new people, we organized some ice-breaker activities for the students at their first combined session. After situating the students with their respective teammates and going over the project brief with them, we led them in three activities: 
1. Everyone (students, teaching assistants, and instructors) stood in a big circle and each had to answer, out loud, the questions "If you were a tool, what kind of tool would you be, and why?"

2. Each team completed to build the tallest tower out of dry spaghetti and marshmallows.

3. Each team was given 20 minutes to get to know each other and come up with a list of five things all of the members have in common, and then present this to the rest of the students. Our hope for this activity was that it would also get the students thinking about the project objective.

We were pleased with the response from the students to these ice-breakers. The different teams appeared to work well together, and all of the students contributed to the activities.

\section{Project Proposals}

Each team was required to submit a proposal of their ideas one month into the project. This allowed us to check on their progress and assess any of the above concerns. Each team was to describe four distinct project ideas in their proposals, and then indicate which one of the four was their preferred idea. This forced the students to explore multiple "solutions" to the assignment and not fixate on just one idea.

We reviewed and discussed each team's proposal while the JHU students were on their spring break. In general, we agreed that the students were not pushing themselves and their ideas far enough. It was also clear that some teams chose to work as individuals, with each member contributing one idea to the proposal, rather than working together to develop all of the ideas. In retrospect, we should have provided the students with more guidance on teamwork and collaboration, and on how to ideate and develop their ideas as a team.

When all of the students had returned from their spring breaks, we met with each team and suggested ways to improve their ideas. For example, one team proposed making a beach umbrella that opened automatically. We suggested they also design it to track the location of the sun and move accordingly so as to provide the most shade. Another team proposed building a small remote-control car and a passive miniature layout of Baltimore on which to run it. We suggested they instead buy some cheap RC cars and put their effort into creating an active layout/obstacle course of Baltimore with sink-holes that open up, pedestrian figures that cross the road, and working traffic lights.

\section{Final Projects and Exhibition}

The students' projects were presented to the public on the evening of April 26, 2018 and remained available for viewing for one week. The floorplan of the exhibit and list of the students' projects are provided in Figure 2. The locations of the projects in the exhibition space were selected by the students based on the needs of each project (e.g. some projects required a separate room, some needed to be near a window). Each project was unique and, while some functioned better than others, they were all very creative. Highlights of the exhibit included

- The Rise N' Shine Machine, designed to make the daily "waking up" experience more enjoyable. This team created a complete mock-up dorm room and a system to 
automatically turn on the lights, raise the curtains, and play the user's favorite music all with the push of a single button.

- The Mechanical Flowers, which included two mechanical flowers with petals that were programmed to open and close simultaneously based on the user's emotional state.

- The Mesozoic Eris, in which a mechanical beast would "eat" the users' smartphones and provide conversation topics in return.

- Twin Swings, suspended from the ceiling and designed to treat users to a light show when they started to swing in sync.

- The Sensitive Monster, who would come out of his cave when spoken to gently, but then scurried away if the noise level became too loud.

and

- Maxbay, an anthropomorphic hugging machine.

On opening night the exhibition space was filled with guests from JHU, MICA, and the surrounding community watching, interacting with, and enjoying the students' creations.

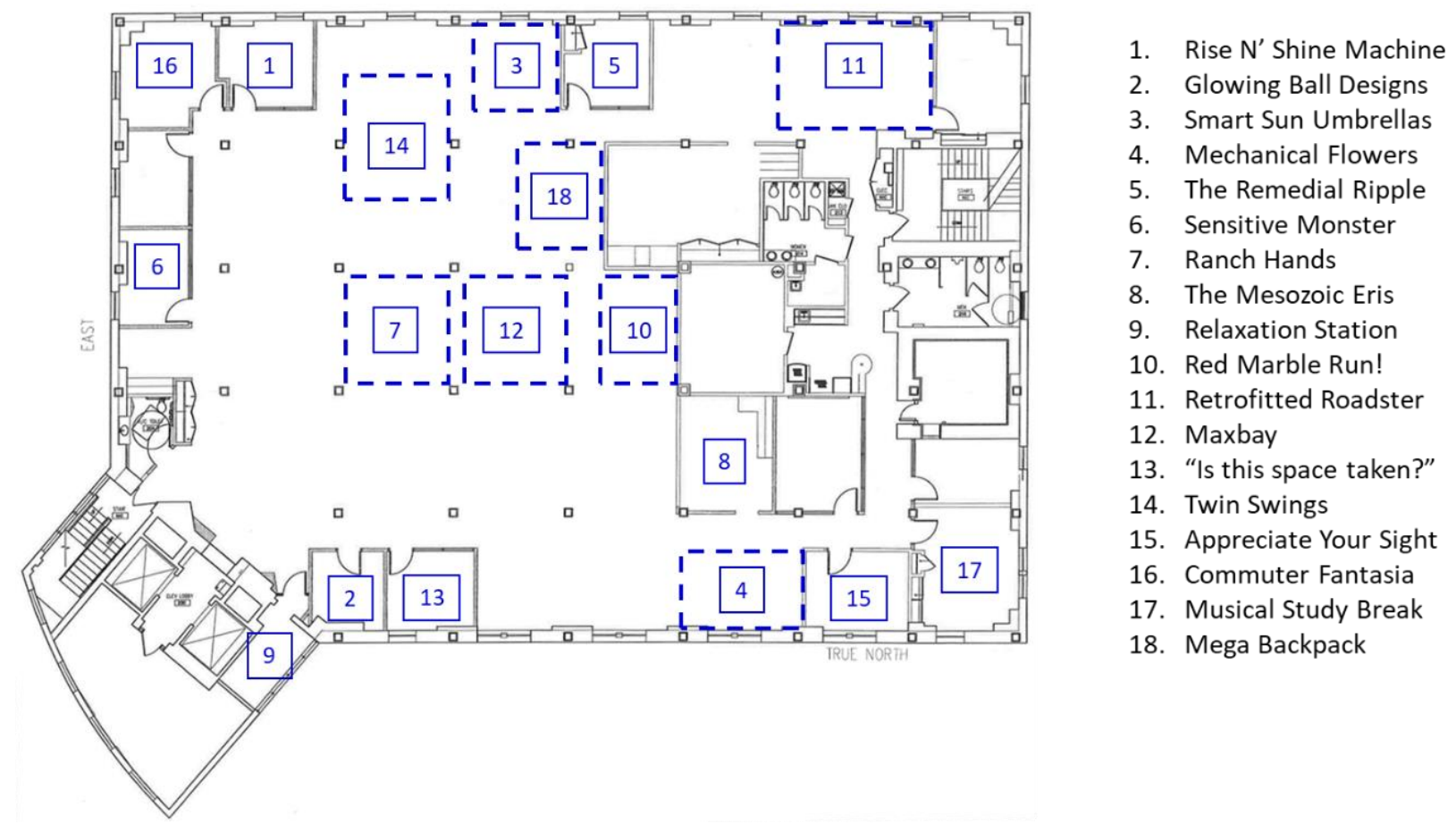

Figure 2 - Floor plan of exhibition with project locations and titles

\section{Challenges and Lessons Learned}

Based on discussions with the students and their final report comments, the "Hack Your Life" design assignment was an overall success. Unfortunately, since this was the first time the JHU MechE Freshman Lab II course was offered, we do not have a "control group" of previous students for comparison. However, the students told us that they were truly challenged by the assignment and felt a strong sense of accomplishment and satisfaction by the end of the semester. We saw the students' engineering, artistic, and interpersonal skills develop throughout the term, and accomplished our goal of creating a memorable and educational interdisciplinary design 
experience for them. We also learned several lessons that will be useful when planning future collaborations.

As expected, the lack of convenient transportation between the campuses proved to be an obstacle for our students. Many teams chose to communicate only through electronic means (e.g. Skype, email, text messaging) during the first month of the project, rather than make the effort to arrange for transportation to meet in person. The students started traveling between JHU and MICA more often as the exhibition date drew closer, but the troublesome transportation options was clearly their biggest complaint with the assignment. For future collaborations, if the JHU and MICA shuttles are still unable to provide full service between the campuses, we will consider reimbursing the students for their associated travel expenses to encourage more inperson team meetings.

Only a few JHU students were unable to participate in the scheduled combined work sessions. These students were disappointed but understood and accepted the situation, and this did not appear to be an obstacle to their teams' project success.

Almost all of the interdisciplinary teams appeared to function well together, but we were aware of a few interpersonal conflicts that arose between JHU and MICA students in some groups. We were able to resolve these conflicts amicably through discussions with the students involved. In retrospect, we should have provided more instruction to the students about effective team work and conflict resolution, and will do so in the future.

Our concern that the JHU students would work exclusively on the engineering and underlying technical fabrication and then the MICA students would add on the aesthetics was justified for some of the teams. In fact, some projects were not able to be realized as the team had hoped because the JHU students spent too long working out technical issues and the MICA students then did not have enough time to add on all of their planned contributions. We may be able to prevent such issues in the future by requiring each member to contribute to both the engineering and the art aspects of their project.

We also should have worked out a strategy among ourselves for advising the teams. Individually we were able to provide the students with different perspective and approaches to solving problems. While it was undoubtedly beneficial to the students to observe our diversity of thought, this sometimes led to us unwittingly giving conflicting advice which confused them. Such confusion may have been avoided had we agreed in advance on an advising strategy to prevent such conflicts.

Only one proposed idea included controversial content, which involved a firearm replica. We agreed that the idea was not appropriate for the exhibition and explained this to the proposing team. They understood our concerns and gladly agreed to pursue a different idea.

The biggest challenge that we did not foresee was the difficulty of instructing 78 students working on 18 very different project ideas. Since each project was unique and each team required our attention and occasional assistance, the sheer number and diversity of problems for which we had to help them was extensive. Perhaps an assignment with a more focused objective 
and with more constraints would have reduced the diversity of problems, enabling us to provide more expedient help to the students.

We also underestimated the negative impact that was caused by our two schools having spring break at different times. Because MICA started their classes one week before JHU, they also had their spring break one week earlier. In planning the assignment we thought the JHU students would continue working on their projects while the MICA students were on break, and vice versa. In reality, neither group of students made much progress during these two weeks and the momentum that had been building during the first half of the semester diminished significantly.

Conclusions and Suggestions

The JHU-MICA "Hack Your Life" design project assignment was a success and a great learning experience for the students and instructors. While we would enjoy collaborating again on another design project assignment, we would want to make some changes to its implementation. We have also discussed bringing our students together for a shorter but more intense hackathon-style design project instead of a semester-long assignment.

For those instructors who are considering assigning an interdisciplinary design project, we offer the following suggestions:

- Start planning early. We started laying the groundwork for our collaboration more than one year before assigning it to our students and were very grateful that we began when we did.

- Choose an assignment with a focused objective and a clear set of specifications. As others [4], [5] have noted, this is can be challenging. However, in our case we suffered by making the project objective too open-ended.

- Introduce the project assignment to the students with a kick-off meeting/event that includes some ice-breaker activities.

- Provide the students with abundant instruction on teamwork and effective collaboration. Gorbet et al. [6] offer several excellent recommendations in this regard.

- Provide the students with abundant instruction on ideation.

- Develop a strategy to prevent the instructors from giving teams conflicting advice.

- Do not underestimate the importance of providing the students with convenient transportation options.

References

[1] H. Bridle, A. Vrieling, M. Cardillo, Y. Araya, and L. Hinojosa, "Preparing for an interdisciplinary future: A perspective from early-career researchers," Futures, vol. 53, pp. 22-32, 2013.

[2] M. Levy, Y. Shlomi, and Y. Etzioni, "When engineering and design students collaborate: The case of a website development workshop," in Knowledge, Information and Creativity Support Systems, S. Kunifuji et al. Eds., Springer, 2016, pp. 431-438.

[3] S. Stawiski, A. Germuth, P. Yarborough, V. Alford, and L. Parrish, "Infusing twentyfirst-century skills into engineering education," Journal of Business and Psychology, vol. 32, pp. 335-346, 2017. 
[4] K. Fleischmann and C. Hutchison, "Creative exchange: An evolving model of multidisciplinary collaboration," Journal of Learning Design, vol. 5, pp. 23-31, 2012.

[5] L. Thigpen, E. Glakpe, G. Gomes, and T. McCloud, "A model for teaching multidisciplinary capstone design in mechanical engineering," in 34th Annual Frontiers in Education, 2004, pp. S2G-1.

[6] R. Gorbet, V. Schoner, and G. Spence, "Impact of learning transformation on performance in a cross-disciplinary project-based course," in 2008 38th Annual Frontiers in Education Conference, 2016, pp. T2C-18.

[7] K. Dartt, R.T. McGrann, and J.T. Stark, "ABET assessment of student initiated interdisciplinary senior capstone project," in 2009 39th IEEE Frontiers in Education Conference, 2009, pp. 1-6.

[8] E. Wuerffel and J. Will, "Engineering in the humanities: Interdisciplinary projects in the arts and engineering," in ASEE Annual Conference and Exposition, Seattle, WA, June, 2015.

[9] D. Desmond, M. Horton, A. Morrison, and S. Khorbotly, "Robotic football dance team: An engineering Fine-Arts interdisciplinary learning experience," in 2016 IEEE Frontiers in Education Conference, 2016, pp. 1-6.

The authors wish to thank Amy Klainer and Jay Gould for their help in planning and executing the "Hack Your Life" design project. 